\title{
Ocular Trauma Characteristics in Cases Admitted to Alexandria University Main Hospital: A Medicolegal Study
}

\author{
Naglaa M. Salama and Fatma M.M. Badr El Dine1
}

${ }^{1}$ Forensic Medicine and Clinical Toxicology Department, Faculty of Medicine, Alexandria University, Alexandria, Egypt

\begin{abstract}
Introduction: Ocular trauma is a common cause of monocular visual impairment and blindness worldwide, with significant socioeconomic impact.

Aim of the work: Was to describe the pattern of ocular trauma in patients attended the Emergency Section of the Ophthalmology Department of Alexandria University Main Hospital and its medicolegal consequences as a permanent infirmity.

Patients and methods: The study included 82 Egyptian patients (48 males and 34 females)presented to the Emergency Section of the Ophthalmology Department, Faculty of Medicine, Alexandria University in the period from the $1^{\text {st }}$ of August 2013 to the end of January 2014. A specially designed sheet included the personal data, data related to the injury, treatment and outcome.

Results: The age of patients ranged from 6 months to 63 years with a mean of $26.5 \pm 15.9$ years. Males $(58.5 \%)$ outnumbered females $(41.5 \%)$. Majority of injuries were accidental $(56.1 \%)$ followed by assaults (43.9 \%). Street injuries represented the highest percentage $43.9 \%$ of ocular trauma. Regarding the causative instruments, the most commonly involved was blunt objects ( $43.9 \%$ of cases) followed by sharp objects $(31.7 \%)$. Closed globe injuries (CGI) accounted for the majority of admitted patients $(68.3 \%$ of all eyes) while open globe injuries (OGI) represented $31.7 \%$. Permanent infirmity was found in $46.34 \%$ of cases.

Conclusion: The results of the present work indicated that ocular trauma is a significant cause of visual loss and infirmity among Egyptian population. The study demonstrates the need for primary prevention and control measures.
\end{abstract}

Keywords Ocular trauma, Accidental, Assaults, Visual outcome, Infirmity, Alexandria, Egypt

\section{Introduction}

$\mathrm{O}$ cular trauma is a common cause of monocular visual impairment and blindness worldwide, with significant socioeconomic impact (Negrel, 1997).There are numerous individual reports on ocular trauma. WHO has reported 55 million eye injuries causing restriction of daily activities, of which 1.6 million go blind every day (Negrel and Thylefors, 1998).

In the United States, approximately 2 million eye injuries occur every year, of which more than 40 thousand result in permanent visual impairment (Mc Gwin et al., 2005). In addition to the impact on the affected individual, there are profound social implications regarding the lost productivity by young men and the requirement of caring facilities and rehabilitation for the elderly. Therefore, knowledge of the causes of ocular trauma is essential for proper management of patients and future prevention of the injury (Nelson et al., 1989; Soliman and Macky, 2008).

All ocular structures are vulnerable to injury (Cockerham, 1983). Eye Injuries were classified into open globe and closed globe based on the Ocular Trauma Classification (Kuhn et al., 1996). An open globe injury is defined as a full thickness injury of the cornea and/or the sclera, whereas a closed globe injury represents a contusion injury or a lamellar laceration (partial thickness wound of the eyeball). 
Ocular trauma can lead to group of complications including corneal lacerations, traumatic cataract, retinal detachment, avulsion of the optic nerve and intra-ocular foreign bodies (Jonas et al., 2000; Girkin et al., 2005).

The incidence of eye injuries may be higher in developing countries; however, little information is available regarding their epidemiology in these countries (Soliman and Macky, 2008; Cillino et al., 2008).To the best of our knowledge, there is no published literature about the ocular trauma and the resultant infirmity in Alexandria University Main Hospital. Thus, the aim of the present study was to describe the pattern of ocular trauma in patients who attended the Emergency Section of the Ophthalmology Department of AlexandriaUniversityMain Hospital according to age, sex, place of trauma, type of injury, causative instruments, treatment received and permanent infirmity.

\section{Patients and Methods}

The present study was performed on 82 Egyptian patients (48 males and 34 females) presented to the Emergency Section of the Ophthalmology department, Faculty of Medicine, Alexandria University in the period from the $1^{\text {st }}$ of August 2013 to the end of January 2014. After approval of the Ethic Committee of Alexandria Faculty of Medicine, informed consent was taken from the patients or their relatives before clinical examination.

All patients with ocular injury were thoroughly examined by an ophthalmologist.

Trauma with Closed Globe was classified as (Pieramici et al., 1997):

- Contusioncaused by a blunt object

- Lamellar laceration causedby a sharp object

- Superficial foreign object

- Mixed

Trauma with Open Globe was classified as (Pieramici et al., 1997):

- Rupturecaused by a blunt object

- Penetration caused by asharp object.

- Mixed

The data were recorded in a specially designed sheet, which include personnel data (age, sex, residence, education and occupation), data related to the injuries (place of trauma, type of injury and causative instruments), treatment whether conservative or surgical and the outcome (any infirmity).
Visual acuity was measured on discharge using the Snellen chart and was categorized as follows:

1. No light perception

2. Light perception

3. Counting fingers to $20 / 200$

4. $20 / 200$ to $20 / 50$

5. $>20 / 40$

Zone of ocular injury was described as follows (Pieramici et al., 1997; Knyazer et al., 2008):

1. External (limited to bulbar conjunctiva, sclera, and cornea)

2. Anterior segment (includes structures of the anterior segment and the pars plicata)

3. Posterior segment (all internal structures posterior to the posterior lens capsule)

\section{Statistical analysis}

The collected data were organized, tabulated and statisticallyanalyzed using statistical package for social sciences (SPSS) version 20. The level of significance was set at $\mathrm{P}$ value $<0.05$. The correlation coefficient was done by changing the categorized data into numerical data, then the significant risk factors was entered in a regression model (Multivariate analysis) to define the most significant risk factors, these significant risk factors if found in one patient it will cause infirmity.

\section{Results}

\section{Age distribution}

The age of patients ranged from 6 months to 63 years with a mean of $26.5 \pm 15.9$ years. High percentage of patients were in the age group less than 18 years $(13.4 \%$ in the age group $<6$ years (preschool) and $24.4 \%$ in the age group 6-18 years (school)) (Table 1).

\section{Sex distribution}

In the present study males outnumbered females in the prevalence of eye trauma with a percentage of $58.5 \%$ vs. 41.5\% (Table 1).

\section{Residence}

Patients from rural areas represented $52.4 \%$, while those from urban areas constituted $47.6 \%$ (Table 1 ).

\section{Level of education}

Non-educated (illiterate and those can read and write) constituted high percentage of cases $41.5 \%$, followed by patients with secondary education (39\%) (Table 1). 


\section{Occupation}

Nearly half of the patients injured in this study were workers $(22 \%)$ and housewives $(26.8 \%)$ (Table 1$)$.

\section{Manner of ocular injury}

As regards the manner of ocular injury, the accidental trauma was the highest $(56.1 \%)$ followed by assaults $(43.9 \%)$ (Table 2).

\section{Place of ocular trauma}

Table 2 shows that outdoors ocular injuries represented the highest percentage $(87.8 \%)$ and street injuries represented $43.9 \%$ of all ocular trauma.

\section{The causative instruments}

The commonest cause of injury were from blunt objects (43.9\% of cases) and sharp objects (31.7\%). Gunshots accounted for $9.8 \%$ of eye injuries (Table 2).

\section{Time delay between trauma and arrival to Emergency Section of the Ophthalmology Department}

Table 2 showed that $63.4 \%$ of the cases presented to the eye clinic within 8 hours of eye injury, while delay of medical intervention (more than 24 hours) happened in $9.8 \%$ only of all injured cases.

\section{Laterality}

Single eye affection (either right or left eye) accounts for the majority of cases $87.8 \%$, while bilateral affection represents only $12.2 \%$ of cases (Table 2 ).

\section{Injury classification}

Closed globe injuries (CGI) accounted for the majority of admitted patients (68.3\%) while open globe injuries (OGI) represented 31.7\% (Table 3). As regard closed globe injury, the contusions represented $58.9 \%$ followed by lamellar lacerations $26.8 \%$ (partial-thickness wounds of the cornea or sclera) (Table 3 ).

Table 3 shows that penetration by sharp object represented the highest percentage $57.7 \%$ of (OGI) followed by rupture caused by blunt object $30.8 \%$.

\section{Visual acuity examination}

Table 4 revealed that $29.3 \%$ of cases had visual acuity of (counting fingers to $-20 / 200$ ), while $22 \%$ of all cases had light perception.

In 12 cases, the visual acuity was not measured due to either age, irritability of the patients after ocular trauma, severe agony and uncooperative patients.

\section{Zone of injury}

Closed and open globe injury affecting zone I (conjunctiva, cornea and sclera) were found in $53.65 \%$ and $19.51 \%$ of the cases of ocular trauma respectively. Involvement of zone III (posterior segment)in CGI and OGI was the least (each was 4.87\%) (Table 5).

\section{Treatment}

Table 6 shows that $63.4 \%$ of cases received conservative treatment while $36.6 \%$ required surgical intervention.

\section{Outcome}

Table 7 reveals that permanent infirmity occurred in $53.7 \%$ of patients with ocular trauma.

Table 8 demonstrates that significant correlation was found between the occurrence of permanent infirmity in patients with ocular trauma and age; the occurrence of infirmity is more risky in older age than in the younger age groups.

Male are susceptible to develop infirmity after eye trauma more than females $(\mathrm{p}=0.013)$.

As regards the occupation, it strongly correlated with development of infirmity; workers, farmers and employee develop permanent infirmity following ocular trauma more than children, students and housewives.

Positive correlation was found between place of occurrence of ocular trauma and infirmity; where infirmity was more likely to happen in outdoors trauma.

In addition, positive correlation was present between the causative instrument and the risk of permanent infirmity; chemicals and gunshots are more dangerous and lead to infirmity than blunt and sharp instruments.

The delay in receiving the adequate care after ocular trauma (more than 8 hours) results in serious complications and may leave permanent infirmity $(\mathrm{p}=0.0001)$.

Positive correlation was detected between the occurrence of infirmity and the type of globe injury ( $\mathrm{p}=$ $0.001)$, as well as the ocular zone injured $(\mathrm{p}=0.001)$.

By applying the multivariate analysis for different factors that can affect the development of permanent infirmity following ocular trauma; it was concluded age, sex , occupation of the patient as well as the place of trauma, causative instrument and the time delay have significant effects on the occurrence of permanent infirmity (Table 9). 
Table 1: Socio-demographic data of the studied cases

\begin{tabular}{|c|c|c|}
\hline & No. & $\%$ \\
\hline \multicolumn{3}{|l|}{ Age } \\
\hline$<6$ years & 11 & 13.4 \\
\hline $6-18$ & 20 & 24.4 \\
\hline $18-30$ & 18 & 22.0 \\
\hline $30-40$ & 17 & 20.7 \\
\hline $40-60$ & 16 & 19.5 \\
\hline Range & \multirow{2}{*}{\multicolumn{2}{|c|}{$\begin{array}{c}0.50-63.00 \\
26.5 \pm 15.9\end{array}$}} \\
\hline Mean \pm S.D. & & \\
\hline \multicolumn{3}{|l|}{ Sex } \\
\hline Female & 34 & 41.5 \\
\hline Male & 48 & 58.5 \\
\hline \multicolumn{3}{|l|}{ Residence } \\
\hline Rural & 43 & 52.4 \\
\hline Urban & 39 & 47.6 \\
\hline \multicolumn{3}{|l|}{ Education } \\
\hline Illiterate & 16 & 19.5 \\
\hline Read and write & 18 & 22.0 \\
\hline Secondary & 32 & 39.0 \\
\hline University & 16 & 19.5 \\
\hline \multicolumn{3}{|l|}{ Occupation } \\
\hline Children & 11 & 13.4 \\
\hline Student & 12 & 14.6 \\
\hline House wife & 22 & 26.8 \\
\hline Worker & 18 & 22.0 \\
\hline Farmer & 17 & 20.7 \\
\hline Employee & 2 & 2.4 \\
\hline Total & 82 & 100 \\
\hline
\end{tabular}

Table 2: Distribution of the studied cases according to the manner of injury, place of ocular trauma, the causative instruments, time delay and laterality

\begin{tabular}{|c|c|c|c|}
\hline \multicolumn{2}{|c|}{ 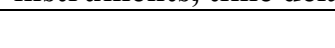 } & No. & $\%$ \\
\hline \multicolumn{4}{|c|}{ Manner of injury } \\
\hline \multicolumn{2}{|c|}{ Homicidal } & 46 & 56.1 \\
\hline \multicolumn{2}{|c|}{ Accidental } & 36 & 43.9 \\
\hline \multicolumn{4}{|c|}{ Place of ocular trauma } \\
\hline \multicolumn{2}{|c|}{ indoors } & 10 & 12.2 \\
\hline \multirow[t]{5}{*}{ Outdoors } & \multirow{5}{*}{$\begin{array}{l}\text { Farm } \\
\text { School } \\
\text { Street } \\
\text { Work } \\
\text { Park/Club }\end{array}$} & 4 & 4.9 \\
\hline & & 10 & 12.2 \\
\hline & & 36 & 43.9 \\
\hline & & 13 & 15.9 \\
\hline & & 9 & 11 \\
\hline \multicolumn{4}{|c|}{ Causative instruments } \\
\hline \multicolumn{2}{|c|}{ Sharp objects } & 26 & 31.7 \\
\hline \multicolumn{2}{|c|}{ Blunt objects } & 36 & 43.9 \\
\hline \multicolumn{2}{|l|}{ Gunshots } & 8 & 9.8 \\
\hline \multicolumn{2}{|l|}{ Chemicals } & 12 & 14.6 \\
\hline \multicolumn{4}{|c|}{ Time delay } \\
\hline \multicolumn{2}{|l|}{$<8 \mathrm{hrs}$} & 52 & 63.4 \\
\hline \multicolumn{2}{|l|}{$8-24$ hrs } & 22 & 26.8 \\
\hline \multicolumn{2}{|l|}{$>24 \mathrm{hrs}$} & 8 & 9.8 \\
\hline \multicolumn{4}{|l|}{ Laterality } \\
\hline \multicolumn{2}{|l|}{ Unilateral } & 72 & 87.8 \\
\hline \multicolumn{2}{|l|}{ Bilateral } & 10 & 12.2 \\
\hline \multicolumn{2}{|l|}{ Total } & 82 & 100 \\
\hline
\end{tabular}


Table 3:Distribution of the studied cases according to the type of globe injury

\begin{tabular}{|c|c|c|}
\hline & No. & $\%$ \\
\hline \multicolumn{3}{|l|}{ Closed Globe Injury (CGI) (68.3\%) } \\
\hline Contusion caused by blunt objects & 33 & 58.9 \\
\hline Lamellar laceration caused by sharp object & 15 & 26.8 \\
\hline Mixed & 8 & 14.3 \\
\hline Total & 56 & 100 \\
\hline \multicolumn{3}{|l|}{ Open Globe Injury (OCI) $(31.7 \%)$} \\
\hline Rupture caused by blunt object & 8 & 30.8 \\
\hline Penetration caused by sharp object & 15 & 57.7 \\
\hline Mixed & 3 & 11.5 \\
\hline Total & 26 & 100 \\
\hline
\end{tabular}

Table 4: Distribution of the studied cases regarding the visual acuity examination

\begin{tabular}{|l|c|c|}
\hline & No. & \% \\
\hline No light perception & 6 & 7.3 \\
\hline Light perception & 18 & 22.0 \\
\hline Counting fingers to 20/200 & 24 & 29.3 \\
\hline $20 / 200-20 / 50$ & 14 & 17.1 \\
\hline$>20 / 40$ & 8 & 9.8 \\
\hline Could not be detected & 12 & 14.6 \\
\hline Total & $\mathbf{8 2}$ & $\mathbf{1 0 0}$ \\
\hline
\end{tabular}

Table 5: Distribution of the studied cases regarding the zone of injury

\begin{tabular}{|l|c|c|}
\hline & No. & \% \\
\hline CGI I & 44 & 53.65 \\
\hline CGI II & 8 & 9.75 \\
\hline CGI III & 4 & 4.87 \\
\hline OGI I & 16 & 19.51 \\
\hline OGI II & 6 & 7.31 \\
\hline OGI III & 4 & 4.87 \\
\hline Total & $\mathbf{8 2}$ & $\mathbf{1 0 0}$ \\
\hline
\end{tabular}

Table 6: Distribution of the studied cases regarding the type of treatment received

\begin{tabular}{|l|c|c|}
\hline & No. & \% \\
\hline Conservative & 52 & 63.4 \\
\hline Surgical & 30 & 36.6 \\
\hline Total & $\mathbf{8 2}$ & $\mathbf{1 0 0}$ \\
\hline
\end{tabular}

Table 7: Distribution of the studied cases regarding the outcome

\begin{tabular}{|l|c|c|}
\hline & No. & \% \\
\hline Infirmity & 38 & 46.3 \\
\hline No infirmity & 44 & 53.7 \\
\hline Total & $\mathbf{8 2}$ & $\mathbf{1 0 0}$ \\
\hline
\end{tabular}

Table 8: Correlation between infirmity and different factors

\begin{tabular}{|l|c|c|}
\hline & $\mathbf{R}$ & $\mathbf{P}$ \\
\hline Age & 0.421 & $0.003^{*}$ \\
\hline Sex & 0.336 & $0.013^{*}$ \\
\hline Occupation & 0.352 & $0.039^{*}$ \\
\hline Place of trauma & 0.41 & $0.007^{*}$ \\
\hline Causative instruments & 0.558 & $0.001^{*}$ \\
\hline Time delay & 0.858 & $0.0001^{*}$ \\
\hline Type of globe injury & 0.622 & $0.001^{*}$ \\
\hline Zone of injury & 0.56 & $0.001^{*}$ \\
\hline
\end{tabular}

$R$, correlation coefficient; $P$, Probability; *, Statistically significant at $p<0.05$, strong correlation when $P<0.01$ 
Table 9: Multivariate analysis of different factors affecting the occurrence of permanent infirmity.

\begin{tabular}{|c|c|c|c|c|c|}
\hline \multirow{2}{*}{ Model } & \multicolumn{2}{|c|}{ Unstandardized Coefficients $^{\mathbf{a}}$} & \multirow{2}{*}{$\begin{array}{c}\text { Standardized Coefficients }^{\mathbf{a}} \\
\text { Beta }\end{array}$} & \multirow{2}{*}{$\mathbf{t}$} & \multirow{2}{*}{ Sig. } \\
\hline & $\mathbf{B}$ & Std. Error & & & \\
\hline (Constant) & 1.309 & 0.133 & & 9.848 & $0.0001 *$ \\
\hline Age & 0.002 & 0.004 & 0.070 & 0.576 & 0.567 \\
\hline Sex & 0.11 & 0.21 & 0.136 & 2.65 & $0.012 *$ \\
\hline Occupation & 0.107 & 0.165 & 0.221 & 0.98 & 0.113 \\
\hline Place of trauma & 0.21 & 0.266 & 0.108 & 0.88 & 0.366 \\
\hline Causative instruments & 0.103 & 0.036 & 0.65 & 3.65 & $0.001 *$ \\
\hline Time delay & 0.014 & 0.004 & 0.449 & 3.718 & $0.0001^{*}$ \\
\hline
\end{tabular}

a, Dependent Variable: Infirmity

\section{Discussion}

Ocular trauma is an important, preventable, worldwide public health problem (Whitcher et al., 2001).Ocular injuries are an important cause of visual impairment, with significant socioeconomic impact (Negrel and Thylefors, 1998).

The incidence of ocular injuries is more in developing countries and it consists a preventable cause of monocular visual impairment and blindness (Tesyafe and Bejiga, 2008).

All ages were found susceptible to ocular trauma. However the mean age in the present study was $26.5 \pm 15.9$ years with $37.8 \%$ in the age groups less than 18 years $(13.4 \%$ in the age group $<6$ years and $24.4 \%$ in the age group 6-18 years). This could be explained by high incidence of home violence and the fact that Egyptians start to work at young age because of the socioeconomic condition. In addition, this relatively high proportion of ocular injuries among children may be attributed to lack of parental supervision during play and other activities, whether indoors or outdoors.

In agreement with the present work, Soliman and Macky (2008) who studied the pattern of ocular trauma in Egypt among cases admitted to Kasr El Aini hospital found that mean age in their study was 22 years, and $49.7 \%$ of all cases were younger than 18 years.

In addition, Ahmed and Zaki (2013) who studied ocular injuries during the 2011 revolution in Egypt found that the mean age was 22.5 years. This was due to the younger age groupwho participated in the protests of the revolution.In contrast to the finding of the present work, Cillino et al.,(2008)who studied the epidemiological characteristics and visual outcome of patients hospitalized for ocular trauma in a Mediterranean area during five-year, found that the mean age was $35.6 \pm 21$ with slight predominance in the second to fifth decade. These different results may be due to the difference in the sample size and the duration of the research.

As regard sex, males constituted $58.5 \%$ while females constituted $41.5 \%$. This result was in close relation with Vats et al.,(2008) who studied the epidemiology of ocular trauma in an urban slum population in Delhi, India. They found that the incidence of ocular trauma were $55.6 \%$ in males and $44.45 \%$ in females. On the other hand, other studies (Wasfy et al.,
2009, Lima-Gómez et al., 2010 and Addisu 2011) showed big difference in the percentage of trauma between males and females. Addisu (2011) who conducted a study in Grarbet Hospital, Butajira, Central Ethiopia found that $75 \%$ of the studied patient were males with male to female ratio 3:1. Also Lima-Gómez et al.,(2010) who evaluated patients with ocular trauma attending a general hospital in Mexico City between 1995 and 2008 , found that $80.2 \%$ of their patients were males. The same was found by Wasfy et al., (2009) who conducted a study in Upper Egypt and found that79.8\% of patients were males.

In the present study, it was found that $52.4 \%$ of cases were from rural area and $47.6 \%$ from urban area with a ratio of 1.1:1.This result was in agreement with Cillino et al., (2008) who found that rural to urban ratio was 5.5: 4.2. This may reflect great exposure to dangerous situation in rural areas. In addition, Wang et al., (2012) found that patient from rural area (2466 patients) were more than those from urban area (1973 patients).

Regarding the educational level it was found that ocular injury was more common among noneducated (illiterate and those who can just read and write) who constituted $41.5 \%$ that may be explained by lower socio economic condition of these categories with more involvement in violent attack.

In the current study, it was found that the main burden of ocular injury has been found to fall on housewives and workers. A possible explanation for the higher involvement of housewives includes domestic related accident and home violence, while workers can get injured during dealing with machines and rough instruments.In contrast to the findings of this work, Wang et al., (2012) found that country man constituted the majority of their patients followed by military personals. Also Soliman and Macky (2008) reported that workers and students were more encountered among patients with ocular injury.In addition, McCarty et al., (1999) found that the work place accounted for the majority $(60 \%)$ of eye injury followed by home during their study on ocular trauma in Australia.

As regards the manner of injury, $43.9 \%$ of patients were injured accidentally while assaults were responsible for about $56.1 \%$ of ocular injuries. On the 
other hand, Ahmed and Zaki (2013) reported that accidental ocular injuries were more common than assaults during their studies from 2006 to 2010. They also reported that during Egyptian revolution 2011, there was significant increase in the percentage of homicidal ocular injury.

In the present study, it was found that outdoors ocular injuries represented the highest percentage $(87.8 \%)$ and street injuries alone represented $43.9 \%$ of all ocular trauma. This could be explained by more exposure to violent action in the street. In contrast to the finding of the present work, Wasfy et al., (2009)who conducted his study in Upper Egypt where agriculture is the main source of incomereported that the most common place was farm followed by street.

As regard the causative instrument, it was found that blunt instrument was responsible about ocular trauma in $43.9 \%$ of cases while sharp instrument was the cause of injury in $31.7 \%$ of cases. Gunshot was responsible of only $9.8 \%$ of injuries. Similar results were obtained by Wasfy et al., (2009) who found that $63.6 \%$ of ocular trauma was caused by blunt instrument while sharp instrument was responsible about only $17.8 \%$. In addition, Addisu (2011) reported that the main cause of eye trauma was due to blunt instruments.

Remarkably, a significant proportion of the patients $(63.4 \%)$ in this study presented to the eye clinic within 8 hours of eye injury, which may have contributed to the favorable outcome in most of them. Omolase et al., (2011) in their study of pattern of ocular Injuries in Owo, Nigeria found that $37.9 \%$ of patients who presented within 24 hours had much better prognosis than those who presented within and after one week.

In current study single eye affection accounts for the majority of cases $87.8 \%$, while bilateral affection represents only $12.2 \%$ of cases. Soliman and Macky (2008) found that only $4 \%$ of cases suffered bilateral traumatic eye injuries. Also, Addisu (2011)reported that bilateral eye involvement was seen in only $1.5 \%$ of patients in Grarbet Hospital, Butajira, Central Ethiopia over a one year period.

The present study reported that $68.3 \%$ of patients suffered from closed globe injury. This coincides with the results of Wasfy et al., (2009) who reported that 121 out of 184 of their patients suffered from closed globe injury. In contrast to the finding of the present work, Soliman and Macky (2008) found that open globe injury accounted for the majority of admitted patients. In addition, Ahmed and Zaki (2013) reported that patients during the year of Egyptian revolution presented with open globe injuries more than closed globe injuries. This could be attributed to the highincidence of violence and the use of stones and firearmweaponsduring revolution.

Contusions represented only $58.9 \%$ of CGI in the current study. On the other hand,Singh et al (2005) illustrated in their study of ocular trauma in North India that $86 \%$ of CGI was contusion.

In the present study, penetration by sharp object represented the highest percentage $(57.7 \%)$ of OGI. In agreement with this work, Addisu(2011) showed that more than $54.4 \%$ of patients whowere injured by sharp instrument suffered from OGI.This could be related to the high ability of sharp object to pierce and penetrate tissues more than blunt ones.

As regards visual acuity, $29.3 \%$ of all patients were presented with visual acuity; counting fingers up to $20 / 200$ and $22 \%$ of all patients had light perception. Similar to the present study, Cillino et al. (2008) reported that $30.2 \%$ of their patients had visual acuity ranged from $20 / 40-20 / 200$ while $15.5 \%$ of them had visual acuity $\leq 20 / 200$ and $6 \%$ of them had no light perception.

In the present work closed globe injury, that affect zone I (conjunctiva, cornea and sclera) was found in half of the cases of ocular trauma. In addition, most of the open globe injuries (16 out of 26) were zone I. Singh (2005) perceived similar result during his prospective study of the profile of ocular trauma at a tertiary eye center in India over one year. He reported that most of the open globe injuries were zone I (50.8\%). On the other hand, involvement of zone 3 in the current study was found in $9.74 \%$ of all cases. In disagreement with this work, Soliman and Macky (2008) reported that injuries of $31.4 \%$ of all eyes were rupture globe where the injuries occurred in all zones. This may reflect the status of the Department of Ophthalmology of Kasr El Aini Hospital as a center for treating serious cases of eye trauma.

Most of the cases of the present workwere referred from the Emergency Room ER (where they received first aid treatment) to the Emergency Section of the Ophthalmology Department (where treatment had started). The study revealed that $63.4 \%$ of cases received conservative treatment while $36.6 \%$ required surgical intervention. On the other hand, Soliman and Macky 2008 stated that only 16 eyes required medical treatment alone, while 137 eyes required surgical intervention. Singh 2005 reported that all open globe injuries were surgically repaired. These may be attributed to the severity of these cases.

Permanent infirmity occurred in $46.3 \%$ of patients with ocular trauma in this study as moderate and severe cases of ocular trauma were referred to the ophthalmology department, while cases of minortrauma were not referred.

Significant positive correlation was found between the occurrence of permanent infirmity in patients with ocular trauma and age; the occurrence of infirmity was higher with increasing the age which could be attributed to the minority of severity of accidental trauma in children and to the vulnerability of old age and any pre-existing diseases like glaucoma or cataract. Ahmed and Zaki (2013) reported a controversial result; they found that most cases with infirmity had occurred in youth during the 2011 revolution in Egypt as this is the age of passion and courage.

The present work showed that males, specifically workers and farmerswere more susceptible to develop infirmity after eye trauma especially in cases of 
outdoor trauma. This could be attributed to the involvement of male in occupational exposure, participation in dangerous situations, alcohol use and risk-taking behaviors(Fong, 1995; Fong and Taouk, 1995; McCarty et al., 1999).

The positive correlation between infirmity and cases exposed to eye trauma by gunshot or sharp instrument in this study may be referred to the severity of injuries caused by these types of instruments. The current study reported positive correlation between the occurrence of permanent infirmity and the type of globe injury as well as the zone of injury; all cases of open globe injury zone III had infirmity.

In this work, it was also found that the correlation between infirmity and time delay before seeking medical intervention was positive. This result was expected as rapid medical intervention usually decreases the risk of infection and complications.

In conclusion, different factors were found to affect the occurrence of permanent infirmity; the age, sex of the patients, the occupation, place of trauma, causative instruments as well as the time delay. Health education and safety strategies should cover not only workplace but also high-risk activities in street or school. Avoidance of hazardous toys and furniture, and close supervision of play activities by parents and caretakers for prevention of eye injury in pediatric group. The necessity of seeking professional medical help immediately after injury and the danger of delaying treatment should also be stressed.

\section{Acknowledgement}

Authors of this study would like to express their grateful thanksto Dr. Nader H. Bayoumi, assistant professor of Ophthalmology, for providing the necessary support for conducting the research.

\section{References}

Addisu Z (2011): Pattern of ocular trauma seen in Grarbet Hospital, Butajira,Central Ethiopia. Ethiop J Health Dev: 25(2)150-5.

Ahmed SA and Zaki RG (2013): Forensic analysis of ocular injuries during the 2011 revolution in Egypt. Forensic Sci Int 233:(1-3) 348-54.

Cillino S, Casuccio A, Di Pace F, et al. (2008): A fiveyear retrospective study of the epidemiological characteristics and visual outcomes of patients hospitalized for ocular trauma in a Mediterranean area. BMC Ophthalmol 8:6.

Cockerham GC (1983): Blunt trauma and nonpenetrating injuries of the anterior segment. Ophthalmol90: 140-8.

Fong LP and Taouk Y (1995): The role of eye protection in work-related eye injuries. Aust NZ J Ophthalmol 23:101-6.

Fong LP (1995): Eye injuries in Victoria, Australia. Med J 162: (2):64-8.
Girkin CA, McGwin G Jr, Morris R, et al. (2005): Glaucoma following penetrating ocular trauma: a cohort study of the United States Eye Injury Registry. Am J Ophthalmol 139: 100- 5.

Jonas JB, Knorr HL, and Budde WM (2000): Prognostic factors in ocular injuries due to intraocular or retrobulbar foreign bodies. Ophthalmology 107: 823- 8 .

Knyazer B, Levy J, Rosen S, et al. (2008): Prognostic factors in posterior open globeinjuries (zone-III injuries). Clin Experiment Ophthalmol 36(9): 836-41.

Kuhn F, Morris R, Witherspoon D, et al. (1996): A standardized classification of Ocular Trauma. Ophthalmology 103: 240-3.

Lima-Gómez V, Blanco-Hernández DMR, and RojasDosal JA (2010): Ocular trauma score at the initial evaluation of ocular trauma. Cir $\mathrm{Cir}$ 78:209-13.

McCarty CA, Fu CL, and Taylor HR (1999): Epidemiology of ocular trauma in Australia. Ophthalmology 106:1847-52.

McGwin G, Xie A, and Owsley C (2005): The rate of eye injury in the United States. Arch Ophthalmol 123:970-6.

Negrel AD and Thylefors B (1998): The global impact of eye injuries. Ophthalmic Epidemiol 5:143- 69

Negrel AD (1997): Magnitude of eye injuries worldwide. Community Eye Health Journal10 (24):49-53.

Nelson LB, Wilson TW, and Jeffers JB (1989): Eye injuries in childhood: demography, etiology, and prevention.Pediatrics 84(3):438- 41.

Omolase CO, Omolade EO, Ogunleye OT, et al. (2011): Pattern of Ocular Injuries in Owo, Nigeria. J Ophthalmic Vis Res 6(2): 114-8.

Pieramici DJ, Sternberg P Jr, Aaberg TM, et al. (1997): A system for classifying mechanical injuries of the eye (globe). Am J Ophthalmol123: 820-31.

Singh DV, Sharma YR, Azad RV, et al. (2005): Profile of Ocular Trauma at Tertiary Eye Centre. JK sciences 7: 16-21.

Soliman MM and Macky TA (2008): Pattern of ocular trauma in Egypt. Graefes Arch Clin Exp Ophthalmol 246:205-12.

Tesyafe A and Bejiga A (2008): Ocular injury in a rural Ethiopia community. East Afr Med J85(12):593-6.

Vats S, Murthy GVS, and Chandra M, et al. (2008): Epidemiological study of ocular trauma in an urban slum population in Delhi, India. Indian Journal of ophthalmology 56 (4): 313-6.

Wang JD, Xu L, Wang YX, et al. (2012): Prevalence and incidence of ocular trauma in North China: the Beijing Eye Study. Acta Ophthalmologica 90: e61-e7

Wasfy IA, Wasfy EIA, Aly TA, et al.(2009): Ophthalmic medicolegal cases in Upper Egypt. International Archives of Medicine 2:1. 
Whitcher JP, Srinivasan M, Upadhyay MP (2001):

World Health Organ 79:214-21.

Corneal blindness: a global perspective. Bull

الملخص العربي

خصائص إصابات العين بين مرضى المستشفى الرئيسي الجامعي بالإسكندرية: دراسة طبية شرعية

'نجلاء محمد سلامة و فاطمة محمد مجدي بلر الاين'

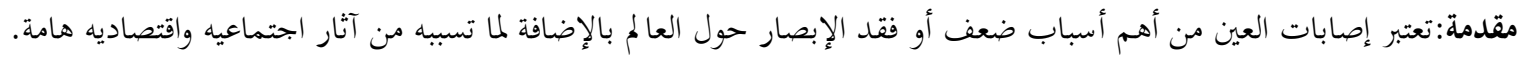

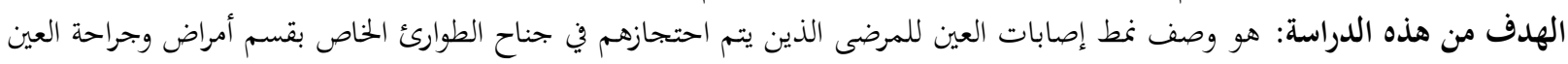
المستشفى الرئيسي الجامعي وأهميته من الناحية الطبية الشرفية.

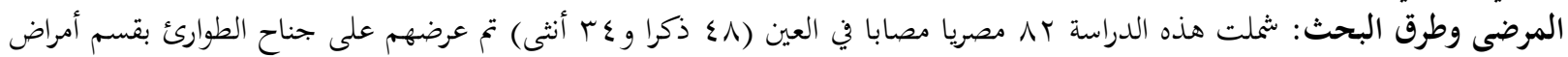

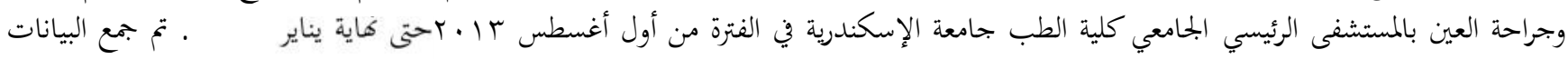

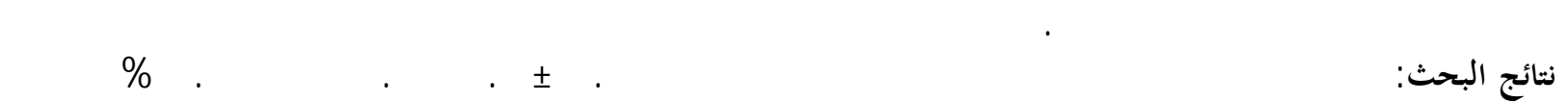

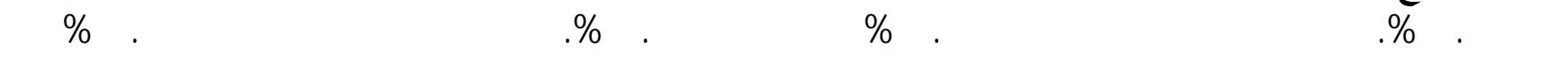

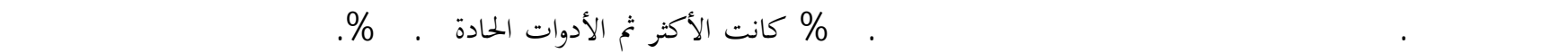

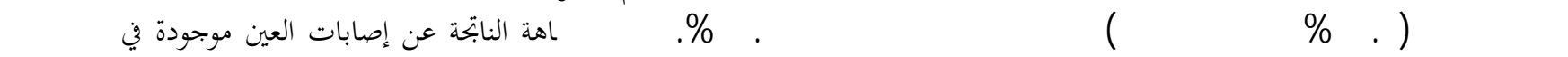

. (\% \% $\%$.

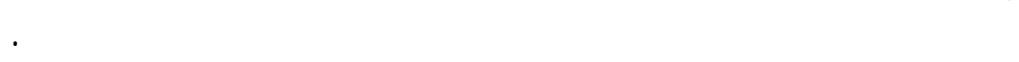

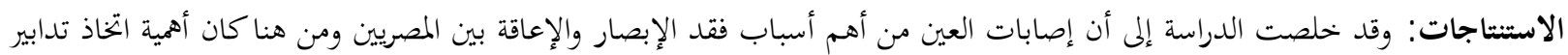

الوقاية الأولة.

1 قسم الطب الثرعي والسموم الإكلينيكية - كلية الطب - جامعة الإسكندرية 